\title{
Espaços para o ensino de biologia e ciências no ensino fundamental e médio: Reflexões acerca das observações durante estágio supervisionado
}

\section{Spaces for the teaching of biology and science in elementary and high school: reflections about observations during supervised stage}

\author{
David Silva Nogueira ${ }^{1}$, João Paulo Martins de Souza ${ }^{2}$, Elizandra Rego de Vasconcelos ${ }^{3}$ \\ ${ }^{1}$ Programa de Pós Graduação em Entomologia do Instituto Nacional de Pesquisas da Amazônia, Manaus-AM; docente no Instituto Federal de \\ Educação, Ciência e Tecnologia do Amazonas, São Gabriel da Cachoeira-AM Brasil. E-mail: dsnogueira@ifam.edu.br *Autor para \\ correspondência \\ 2Instituto de Biologia, Universidade Federal do Amazonas, Manaus-AM Brasil. E-mail: joaopaulo07103@gmail.com \\ Instituto de Biologia, Universidade Federal do Amazonas, Manaus-AM Brasil. E-mail: elizandravasconcelos@hotmail.com
}

\author{
Palavras-chave \\ Ensino-aprendizagem \\ Motivação \\ Educação
}

Para entender mais sobre a relação do espaço de aprendizagem com o processo de ensino é que foi proposto esse trabalho. Ele é composto por relatos obtidos durante o estágio supervisionado l em duas escolas estaduais de Manaus-AM. O acompanhamento foi observacional com pesquisa participativa em que foram observadas as aulas de biologia para alunos de ensino médio, com dois professores que utilizam metodologias diferentes. Também foi feito o acompanhamento e fiscalização de uma feira de ciências para alunos do fundamental II, onde foram observadas a interação dos alunos com o público e a motivação deles em frente a essa estratégia de modificação do espaço convencional de sala de aula. Os alunos do ensino médio se mostraram mais participativos quando o ambiente de sala foi moldado com diferentes estratégias pelo professor e os do ensino fundamental também demonstraram uma maior motivação quando arguidos pelos avaliadores durante a feira de ciências.

\begin{abstract}
The goal of this study is to understand more about the relationship of learning space to teaching process. It consists of reports obtained during the supervised internship I in two public schools in Manaus-AM. The monitoring was observational with participative research. Biology classes for high school students were accompanied, with two teachers using different methodologies, in addition to monitoring and supervision of a science fair for students of elementary school, where the interactions of students with the public and their motivation were observed in front of this strategy of modifying conventional classroom space. High school students were more participative when the classroom environment was shaped with different strategies by the teacher and elementary school students also showed greater motivation when challenged by the evaluators during the science fair.
\end{abstract}

Teaching-learning

Motivation

\section{INTRODUÇÃO}

A biologia está ao nosso redor, em todos os espaços em que estamos, assim como o conhecimento sobre os processos biológicos. Basta observar e perceber cada um deles para, então, termos discernimento e usa-los em nossas experiências cotidianas (ELOIA; ELOIA, 2012).

Para que possamos entender os aspectos relacionados com a biologia, tais como: as plantas do quintal, os pássaros que cantam ao nosso redor etc. É necessário que as informações e conhecimentos obtidos por meio da escola, de um professor, da internet ou mesmo, dos próprios pais sejam compreendidos com sucesso. Ou seja, que estes cheguem para além da transmissão da mensagem e mera recepção pelos estudantes (MARANDINO et al., 2009).

Um fator que devemos considerar para que haja um melhor aprendizado dos assuntos relacionados com a biologia, é a adequação desses assuntos com a própria realidade do aluno, além de se evitar na prática de ensino, o uso dos procedimentos convencionais e decorativos (PINTO et al., 2009).

Além disso, é preciso observar os aspectos psicológicos individuais e o ambiente em que acontece o ensino. Haja vista que a concentração dos alunos depende tanto da motivação sobre o que se aprende, como do bem estar do próprio grupo inserido no ambiente em que se aprende. Esses ambientes de aprendizado sobre as ciências biológicas são inúmeros e, vão desde a tradicional sala de aula até os laboratórios, pátios, jardins até espaços não formais como, por exemplo, o ônibus, a rua e, até mesmo em casa onde se tem acesso a diversas informações, inclusive através de propagandas, novelas, rótulos alimentícios, quadros e fotografias (MARANDINO et 
al., 2009).

O objetivo desse estudo foi verificar o aprendizado, bem como a motivação dos alunos em atividades tanto de ciências como de biologia em diferentes tipos ambientes dentro da própria escola.

\section{MATERIAL E MÉTODOS}

Foi utilizada uma mistura de pesquisa qualitativa, em que se faz um estudo descritivo e não quantitativo sobre o aspecto que se observa, e pesquisa participativa, com a perspectiva fenomenológica, em que o observador está integrado ao meio observado e o registra do ponto de vista do próprio observador, enfatizando o componente subjetivo do comportamento das pessoas (BERGER \& LUCKMANN, 2001; MINAYO, 2002). Assim, utilizou-se como fontes de evidências a observação sistemática e as narrativas de estagiários, relatos de memórias de formação relacionadas à práticas educativas (ARAGÃO, 2011).

"A fim de que as narrativas possam ser utilizadas como fontes de informações acerca do sujeito, de que elas ganhem expressão e reflitam as experiências do narrador, é necessário considerar o contexto em que são produzidas" (QUADROS et al., 2012, p. 391).

As narrativas foram registradas por meio de caderno de campo. Tais registros foram realizados em diferentes ambientes de ensino-aprendizagem em duas escolas estaduais distintas localizadas nas zonas leste e centro-sul do município de Manaus, Amazonas, Brasil.

As atividades foram restritas a aulas teóricas para alunos do ensino médio e, concomitantemente, uma atividade de exposição científica (feira de ciências) para alunos do ensino fundamental II. Foi observada a metodologia didático-prática abordada por diferentes professores acerca do ensino de ciências e biologia atrelada ao uso dos espaços, material e métodos em decorrência da aprendizagem e motivação dos alunos.

A primeira escola, localizada no bairro Cachoeirinha, foram observados estudantes do ensino fundamental em apresentação durante uma feira de ciências, tendo como público alvo tanto os professores como os pais dos alunos $\mathrm{e}$ os próprios alunos do ensino fundamental II. A feira ocorreu no dia 25 de novembro de 2016, com quatro turmas de estudantes, cada uma com um tema diferente: astrologia, história da entomologia médica, doenças amazônicas e cultura indígena.
Já a segunda escola, localizada no bairro Coroado, foram acompanhadas as aulas regulares da disciplina de biologia para turmas de primeiro, segundo e terceiro ano, tanto em sala de aula convencional, quanto em laboratório durante todo o mês de novembro de 2016. Os assuntos abordados foram divisão celular e sistema reprodutivo humano.

\section{RESULTADOS E DISCUSSÃO}

Os resultados aqui apresentados estão organizados em três seções, segregados por escola observada e a junção dos espaços das duas escolas sobre o ensino-aprendizagem dos alunos tanto de ciências, como de biologia.

\section{Escola da Cachoeirinha}

Pôde-se observar que em cada seção montada em sala de aula teve uma repercussão diferente entre os alunos na medida em que ocorreu a apresentação.

Na sala de entomologia médica, o material utilizado foi, em geral, cartazes colados nas paredes com tópicos sobre o tema, e a equipe de alunos realizou a apresentação oral e a exibição de maquetes que ilustraram o conteúdo proposto.

Já na sala sobre astrologia, todas as paredes estavam forradas com tecido preto ornamentado com estrelas prateadas, havia várias maquetes com o sistema solar, satélites e jogos educativos sobre o tema, além de haver um aluno vestido de astronauta que guiava os visitantes por todo o percurso da sala.

"Os dois primeiros alunos da sala de doenças amazônicas demonstraram muita insegurança e nervosismo ao apresentar o conteúdo, mas o avaliador (observador/pesquisador) os ajudou fazendo perguntas sobre o assunto falado com a realidade dos alunos. Isso os deixou mais confortáveis e seguros para comentar sobre o cotidiano de medidas preventivas em relação às doenças" (anotações do estagiário).

"Após o astronauta, o primeiro rapaz que apresentou o tema sobre extraterrestres demonstrou uma forte empolgação $e$ segurança no tema, inclusive interagindo com o avaliador (observador/pesquisador) fazendo perguntas de opinião. A maturidade na forma de repassar o assunto estudado pelo aluno instigou o surgimento 
de um sentimento de aprovação pelo pesquisador" (anotações do estagiário).

A relação de ensino entre o professor e o aluno influência de diversas formas a maneira como esse aluno consegue lidar com o conhecimento obtido para repassá-lo adiante. Pois, como foi observado no primeiro relato, houve nervosismo e insegurança demonstrados pelos alunos no momento da apresentação. Para Freire (2016), isso reflete a "educação bancária", com o qual, esse autor critica todo o tipo de mecanização do ensino. Como os alunos "decoraram" o assunto que a ser abordado, isso trouxe certa insegurança no momento de passar a informação ao espectador e receio de fugirem do tema, cometendo eventuais erros. O medo de errar constrange o indivíduo, mesmo que vários autores defendam o erro como uma forma eficaz de aprendizado (SIERPINSKA, 1989; BARCHELARD, 1996), mas com a presença do diálogo, mesmo que informal, a mecanização pode ser contornada ou mesmo descontruída sem que haja perda em relação ao aprendizado (FREIRE, 1967; LOPES, 1999; CAMPOS, 2002).

Além de analisar como se fala, devemos nos atentar ao que se fala, pois a apresentação dos alunos não pode ser restrita a uma mesma fonte, por que, dependendo do assunto que se fala, podem surgir indagações ou argumentos da memória, que foram consolidados ao longo da experiência de vida. A empolgação e maturidade do aluno da sala de astrologia motivou a curiosidade do avaliador para dispensar mais atenção ao assunto que ele estava discutindo, ou seja, a motivação dele não foi restrita ao que deveria falar, pois notadamente, houve improviso e naturalidade no repasse do conteúdo. Segundo Fortier et al. (1995), a motivação desse aluno pode ser considerada tanto como intrínseca como extrínseca. Intrínseca, pois ele considerou a atividade interessante, envolvente e geradora de satisfação. Extrínseca, pois houve algum tipo de recompensa externa ou material, como no caso da nota. Mas mesmo com a motivação intrínseca, foi notável que o desempenho expressado por ele, não foi pensado na recompensa posterior, e sim, no momento do diálogo em si.

\section{Escola do Coroado}

As aulas foram acompanhadas, em sua maioria em sala de aula formal, sendo que apenas uma delas ocorreu no laboratório de ciências da escola. Tais aulas foram ministradas por dois professores de biologia.

O professor 1, demonstrou, além do domínio do conteúdo, uma maior interação com os alunos, de maneira que, por diversas vezes, trouxe exemplos do cotidiano dos alunos para elucidar os temas abordados, além de realizar rápidas encenações no próprio ambiente de sala para fixação do conteúdo abordado.

\begin{abstract}
"Ao explicar sobre os processos de divisão celular, o professor (1) chamou um dos alunos para "brincar" de cabo-de-guerra. Ele e o professor deram suas mãos $e$ as puxaram em direções opostas para simular a separação das cromátides irmãs. Eles mantiveram seus polegares erguidos $e$ entrelaçados para reforçar que seriam as cromátides antes da separação celular. $\mathrm{Na}$ medida em que cada um colocava força, o restante da turma ria e interagia com a situação. Antes da brusca separação, o professor encerrou a brincadeira, agradeceu ao aluno voluntário, e continuou a ministrar o assunto a partir dessa rápida encenação" (anotações do estagiário).
\end{abstract}

\begin{abstract}
"O professor (2), chegou em sala, ligou o computador e ficou sentado à mesa, enquanto os alunos resolviam um exercício. A falta de motivação dos alunos, frente à ação do professor, causou um descontrole da turma, de maneira que vários alunos conversaram e riam em tom alto. Dois alunos estavam sentados no braço da carteira, uma garota tirava fotos, alguns usavam a internet do celular, outros ouviam música com fone de ouvido. Em momento algum o professor demonstrou estar preocupado com a ação descontrolada da turma" (anotações do estagiário).
\end{abstract}

Na encenação narrada acima, é possível percebermos como uma atitude, mesmo que simples pode modificar a forma de aprendizado, mesmo que seja no mesmo ambiente rotineiro para uma turma de alunos do ensino médio. É sabido que o ambiente em si pode exercer influência na eficácia do ensino, mas a capacidade que o professor tem de influenciar o mesmo ambiente rotineiro na forma de repasse do conteúdo pode ser muito mais eficaz no processo de ensinoaprendizagem. De acordo com Ames (1992), a respeito da aprendizagem e da motivação dos estudantes, a sala de aula exerce uma forte influência para o seu nível de envolvimento. Mas esse estilo de envolvimento refere-se às ações do professor em desenvolver determinadas estratégias de ensino e motivação (REEVE, 1998).

Podemos notar que o envolvimento e participação dos alunos são diretamente relacionados às ações dos 
professores. Mediante a uma encenação sobre o conteúdo ou mediante ao descaso em relação aos estudantes como um todo. Alguns autores (VYGOTSKY, 1991; KLEIN, 1996) defendem a ideia de que a aprendizagem pode ser o resultado das interações sociais, ou das interações com o próprio ambiente em que o aluno está inserido (LENCASTRE, 2006), como por exemplo, a relação professor-aluno em sala, pois essa interação traz uma ideia de mediação e internalização do que foi ensinado como aspectos fundamentais para a aprendizagem. Já o descaso em relação as turmas do segundo professor, do ponto de vista do aluno, isso poderá comprometer o aprendizado, além de tornar os assuntos de biologia mais maçantes e desgastantes, pelo comprometimento da aprendizagem de conhecimentos básicos da biologia. Do ponto de vista do professor, a rotina de trabalho e o comportamento de alunos considerados problemáticos em sala de aula, determinam um desânimo docente que acaba atingindo todas as turmas que aquele professor leciona (MIRANDA; SANTIAGO, 2010).

As aulas do professor 1, em geral, foram narradas de forma dinâmica, com exemplos que interagiram com a realidade dos alunos, como por exemplo, a citação do nome do cantor Michel Teló, para os alunos associarem com a fase "telófase" de divisão celular. Bruner (1997) comenta a respeito do modelo de narrativa que foi utilizada, em que representa uma das maneiras de explorar "mundos possíveis" a partir do contexto da necessidade imediata, que foi a memorização do processo de divisão celular por associação.

Mesmo que Freire (2016) defenda a ideia de existir algo além dos assuntos de sala de aula, que envolvam o diálogo com a realidade dos alunos e discorde sobre o método de eficácia da "educação bancária", em que consiste em uma relação ensino-aprendizagem mecanizada, em quem a minoria opressora controla a maioria oprimida. 0 método de memorização utilizado pelo professor 1 pareceu agradável aos alunos que se mantiveram prestando atenção ao que o docente falava e permaneceram participando da aula ministrada. Já o descaso com a turmas do professor 2, além de estar relacionado com essa educação tradicional e opressora, pode estar relacionado com a desmotivação do profissional docente, que em suma, é refletida em suas ações ou indiferença dentro de sala.

De acordo com Silva (2012), a baixa remuneração dos professores os obriga a ocuparem uma carga horária maior de aulas na escola, ou mesmo a terem outro emprego para complementar a renda mensal. Esses fatores, além da ausência na criação dos filhos, tempo de descanso e lazer comprometido e estresse diário da profissão, afetam diretamente na qualidade do ensino.

A única aula de laboratório observada ao longo do estudo, foi organizada pelo professor 2 , mas que, em tese, não ocorreu uma aula realmente prática, e sim, uma aula teórica com a utilização de um projetor de slides. Nessa aula, já houve uma maior motivação por parte do professor em expressar o tema de sistema reprodutor humano, pois alguns temas interagiram com os alunos, os fazendo dispensarem mais atenção ao que estava sendo ensinado. Piadas sobre "leite, frauda e choro", "nutrição de espermatozoides e não da namorada" e "mudanças na puberdade", chamaram a atenção, pois o professor os expressou de maneira cômica, assim como Byington (1996) comenta que se o referencial pedagógico (professor) se basear em um ensino lúdico, emocional, cômico e dramático, atrairá mais a atenção dos alunos, bem como construirá uma relação mais forte entre o aluno, a classe e o próprio professor.

\section{Os espaços na relação ensino-aprendizagem}

Os espaços e as formas de trabalho que moldam os espaços do ensino e aprendizagem podem ter grande influência na vida dos estudantes. E mesmo que o evento da feira tenha sido realizado no espaço habitual de sala de aula, a experiência vivida pelos alunos foi diferenciada, o que causa uma mudança na rotina e um maior envolvimento da turma no estímulo do trabalho em equipe.

De acordo com Mancuso (2000) e Lima (2008), as feiras de ciências podem causar nos estudantes as seguintes mudanças: o crescimento pessoal e a ampliação dos conhecimentos; a ampliação da capacidade comunicativa; mudanças de hábitos e atitudes; o desenvolvimento da criticidade; maior envolvimento e interesse; exercício da criatividade moldando as inovações e maior politização dos participantes.

A quebra da rotina em eventos locais escolares pode causar uma modificação do ambiente comum para que haja uma nova perspectiva de ensino em sala, diferentemente do ensino convencional (ESTEBAN, 2002). Quando há uma modificação do equilíbrio cotidiano dos alunos em relação a um método de aprendizado diferenciado, podemos considerar que há, de certa maneira, aprendizado pelas novas experiências, visto que, de acordo com Piajet (1976), o equilíbrio não retorna ao mesmo ponto em que iniciou, e sim, para uma nova fase, ou novo nível de aprendizado, em que houve um acréscimo incorporado às estruturas mentais e cognitivas de cada aluno.

\section{CONSIDERAÇÕES FINAIS}

É sabido que uma boa relação professor-aluno mediante a um ambiente de ensino saudável favorecem o processo de ensino-aprendizagem de uma maneira que possa preparar 
esses alunos a aprender a aprender e gostar do que se está aprendendo.

O espaço de aprendizagem pode ser experimentado pelo professor na utilização de novas estratégias de ensino que acolham os alunos de maneira diferenciada, causando uma quebra de rotina para fixação da mensagem repassada.

Além da estratégia de modificação dos espaços de aprendizagem, deve-se prevalecer sempre o respeito e a aceitação do professor com cada aluno e dos alunos com eles mesmos, para que haja uma boa relação que transforme o momento do aprender em um momento especial e significativo.

\section{REFERÊNCIAS}

AMES, Carole. Classroom: Goals, structures, and student motivation. Journal of Educational Psychology, v. 84, n. 3, p.261-271, 1992.

ARAGÃO, Rosália M. R. de. Memórias de formação e docência: bases para pesquisa narrativa e biográfica. In: CHAVES, Silvia Nogueira; BRITO, Maria dos Remédios de. Formação e docência: perspectivas da pesquisa narrativa e autobiográfica. Belém: UFPA/CNPq, CEJUP, 2011.

BACHELARD, Gaston. A formação do Espírito Científico: Contribuição para uma psicanálise do conhecimento. (Tradução de Estela dos Santos Abreu) Rio de Janeiro: Contraponto. 315 p., 1996.

BERGER, Peter L.; LUCKMANN, Thomas. A construção social da realidade: tratado de sociologia do conhecimento. Petrópolis: Vozes, 2001.

BRUNER, Jerome. Atos de significação. Porto Alegre: Artmed. 142 p., 1997.

BYINGTON, Carlos Amadeu B. Pedagogia Simbólica: a construção amorosa do conhecimento de ser. Rio de Janeiro: Rosa dos Tempos, 333p., 1996.

CAMPOS, Marcio D'Olne. Etnociências ou etnografia de saberes, técnicas e práticas. In: AMOROSO, Maria Christina de Mello; MING, Lin Chau; SILVA, Sandra Pereira (Orgs.). Métodos de coleta e análise de dados em etnobiologia, etnoecologia e disciplinas correlatas. São Paulo: Unesp/ CNPQ, 2002, p. 46-92.

ELOIA, Suzana Mara Cordeiro; ELOIA, Sara Cordeiro. A importância da disciplina de biologia associada à vida saudável na visão dos estudantes. Essentia, v. 13, n. 2, p.81-94, 2012.

ESTEBAN, Maria Teresa. A avaliação no processo ensino/aprendizagem: os desafios postos pelas múltiplas faces do cotidiano. Revista Brasileira de Aprendizagem Aberta e a Distância, v. 19, p.129-137, 2002.

FORTIER, Michelle S.; VALLERAND, Robert J.; GUAY, Frédéric.
Academic motivational and school performance: Toward a structural model. Contemporary Educational Psychology, v. 20, n. 3, p.257-274, 1995.

FREIRE, Paulo. Educação como prática da liberdade. Rio de Janeiro: Paz e Terra, 150 pp., 1967.

FREIRE, Paulo. Pedagogia do oprimido. Rio de Janeiro: Paz e Terra, 288 pp., 2016.

KLEIN, Lígia Regina. Alfabetização: quem tem medo de ensinar. São Paulo: Cortez,160 pp., 1996.

LENCASTRE, Marina Prieto Afonso. Ética ambiental e educação nos novos contextos da ecologia humana. Revista Lusófona de Educação, v. 8, p.29-52.

LIMA, Maria Edite Costa. Feiras de ciências: o prazer de produzir e comunicar. In: PAVÃO, Antonio Carlos; FREITAS, Denise de. Quanta ciência há no ensino de ciências. São Carlos: EduFSCar, 2008, p. 195-205.

LOPES, Alice Ribeiro Casimiro. Pluralismo cultural em políticas de currículo nacional. 1999. In: MOREIRA, Antonio Flavio Barbosa. (Org.). Currículo: políticas e práticas. Campinas: Papirus, 1999, p. 59-80.

MANCUSO, Ronaldo. Feiras de ciências: produção estudantil, avaliação, consequências. Contexto Educativo: Revista digital de Educación y Nuevas Tecnologías, v. 6, n. 1, p.1-5, 2000.

MARANDINO, Martha; SELLES, Sandra Escovedo; FERREIRA, Marcia Serra. Ensino de biologia, histórias e práticas em diferentes espaços educativos. Cortez Editora, 215 p., 2009.

MINAYO, Maria Cecília de Souza. Pesquisa Social: teoria, método e criatividade. Petrópolis, Vozes, 79 pp., 2002.

MIRANDA, Margarete Parreira; SANTIAGO, Ana Lydia. As conversações e a psicanálise aplicada à educação: um estudo do mal-estar do professor e o aluno considerado problema. In: O declínio dos saberes e o mercado do gozo, 8. Proceedings online, 2010.

PIAGET, Jean. A equilibração das estruturas cognitivas: problema central do desenvolvimento (M. M. dos S. Penna, Trad.). Rio de Janeiro: Zahar Editores. 175pp., 1976.

PINTO, T. V.; MARTINS, I. M.; JOAQUIM, W. M. A construção do conhecimento em botânica através do ensino experimental. In: XIII ENCONTRO LATINO AMERICANO DE INICIAÇÃO CIENTÍFICA e IX ENCONTRO LATINO AMERICANO DE PÓS-GRADUAÇÃO, 2009, São José dos Campos. Anais do Congresso, Universidade do Vale do Paraíba.

QUADROS, Ana Luiza; SILVA, Dayse Carvalho da; SILVA, Fernando César; SILVA, Gilson de Freitas; OLIVEIRA, Sheila Rodrigues; ANDRADE, Frank Pereira de; TRISTÃO, Juliana Cristina; SANTOS, Leandro José; ALEME, Helga Gabriela. Professor de ensino superior: o entendimento a partir de 
narrativas de pós-graduandos em química. Educação e Pesquisa, v.38, n.2, p.389-402, 2012.

REEVE, Johnmarshall. Autonomy support as an interpersonal motivating style: Is it teachable? Contemporary Educational Psychology, v.23, p.312-330, 1998.

SIERPINSKA, Anna. Sur um programme de recherche lié à la notion dóbstacle épistemologique. Montreal: Agence $D$ arc (Tradução Méricles T. Moreti e Cláudia R. Flores), 1989. SILVA, D.N. A desmotivação do professor em sala de aula, nas escolas públicas do município de São José dos Campos SP. 2012. 51 f. Monografia (especialização) - . Universidade Tecnológica Federal do Paraná, Paraná, 2012.

VYGOTSKY, L. S. A formação Social da Mente. São Paulo: Martins Fontes, 90 pp., 1991.

Submissão: 29/11/2019

Aprovado para publicação: 19/12/2019 